\title{
Is Selfie Moving Towards Popular Culture? - Application of Selfie Phenomenon and Extension of Digital Self in Television Ads
}

\section{Falguni Vasavada Oza, Mudra Institute of Communication, India Khyati Jagani, Mudra Institute of Communications , India}

\begin{abstract}
Up until the early 2000s the content from television had found space in the internet, especially on the social networking sites where content such as news, soap operas, dramas, and movies, traditionally viewed and consumed on television was now also being consumed online by the consumers. However, recently a reverse phenomenon has been observed, where an internet trend, more specifically a social networking phenomenon namely, selfie, has found a space in the television advertisements, promotional activities and soap operas on televisions. This phenomenon in the last few years has been used extensively for the purpose of advertising and promotions. For instance, in 2015 a soap opera show named, Master Chef India, had announced a contest where, the interested audience were asked to prepare a special dish cooked by them, take a selfie with the dish and send it through Whatsapp. This provides marketer a direct interaction platform with the consumers.
\end{abstract}

One of the factors that determine consumption is the affirmation of identity. Consumers seek to build some sort of congruity between themselves and brand so that the brand they use becomes meaningful to them. Therefore, it is essential for a consumer to select those brands that are in tune with their self-identity. An individual's profile page on various social networking sites is like a reflection of them self and their self image. The digital self is created in the online communication with no intervention of feedback or external environmental factors. The digital self is more of the reflection of one's inner world, which focuses on the thoughts, feelings, emotions and personalities of an individual. The digital self is often represented in a manner in which the negatively perceived physical attribute of a person could be changed into a positively perceived digital representation.

This paper aims to conceptualise how the marketer uses the concept of digital self through the selfie phenomenon in the offline context, and how this has become a part of the popular culture where the digital self is extended from the online sphere to the offline sphere.

Keywords: selfie, popular culture, marketing 


\section{Introduction}

People are learning and practicing a new form of devotion, where they are collectively worshipping their own digital altar selves. Today the consumers are simultaneously both empowered and incarcerated by the Smartphone's on which they are sharing images and pictures of themselves with their loved ones at an unprecedented scale. According to Glum, (2015) an average Gen $Y$ and $Z$ takes around 25,700 selfies in their entire life. According to Thomas (2014) globally people take more than 1 million selfies per day. Brands are taking this as an opportunity to not only reach their consumers but also interact with them and engage them at a more intimate level where now the consumers get to do what they enjoy the most and now they get to do it with their favourite brand. Where the brand merged with the person becomes the object of aesthetic beauty. The merger between the selfies and brands works in perfect sync with each other helping both the stake holders. Thousands of brands have already started to use selfie in their advertising campaigns and have made some of the very successful campaigns.

The selfie phenomenon is being used not only as a part of the storyline of the advertisement but also as a larger marketing strategy in order to interact with the consumers. There are three key causes of adoption of the selfie phenomenon in advertising, for one it is cost effective, two it is easy to instantly share selfies on Facebook, Twitter or Instagram and lastly it has become a part of the popular culture where people have adopted taking their own photos from the various digital devices as a part of their daily life. It is therefore the brands have started designing the selfie ad campaigns bowing to the culture of self-love and self-expression.

Selfie takers have become the owner of their digital identity and testimony of their freedom, selfies are often seen as a sign of narcissism. But the fact remains that selfies reports for more than one-third of all the photographs taken by the people in the ages of $18-24$. The Selfies are not just life seen through the lens; rather it is a life lived through a warm glow of Instagram, Twitter and Facebook. It is a life that is being lived both here and elsewhere; where people get the sensory thrill of living in the moment by recording and sharing every crucial aspect of their lives with the world. It is a life lived in multiple dimensions and multiple realities. Selfies as a phenomenon and trend has been discussed in both the lights of negative behaviour and positive behaviour. However, it is giving the brands a considerable chance to magnify their 
communication. From a content creation standpoint it helps in creating a sense of expectation, fun and cool experience for the consumers.

People have been taking their own photos since the 1800s. However, what has changed at present is that everybody has a digital camera with them at all the times and internet to share their pictures online in real time. The newer apps are now enabling the consumers to take twosided pictures, a photo of them taking a photo. The young consumers' especially digital natives and generation $\mathrm{Z}$ are highly skilled in crafting and editing their photos and in creating their perfect social image. This has brought crucial implications for the marketers on how the consumers portray themselves and what they like to associate themselves with. However, using selfies in the promotional strategies comes with its own set of challenges. Young consumers today especially the teens behave differently than the earlier generations. They have not abandoned Facebook, but they have disseminated their diverse identity across different, more closed and personal networks such as Whatsapp and Snapchat, posing challenge to the advertising (The second self, 2015).

The selfie phenomenon has ushered in a new era of conspicuous consumption on a global scale. Marketers are aware of the fact that this is a 'community' that they can easily tap into. This emerging behaviour presents both an opportunity and a challenge for the brands, which have no control over the integrity, or lack thereof, of the imagery in which they appear. It is an incredibly self-indulgent moment in time, but marketers have always jumped on the bandwagon when it comes to social trends. Thousands of brands have adopted the selfie phenomenon. The brands have been quick to capitalize on the growing self-awareness of the consumers using it in their advertising campaign. Dell, in 2015 launched 'art of the selfie' campaign, where they created a gentle negative message which said that consumers have unhealthy obsession with documenting every minutiae detail of their daily life and needs to join a 'rehab' for those suffering from 'selfie arm' due to taking too many photos. In summer 2014 Calvin Klein launched its underwear campaign using the hashtag \#mycalvins. The selfies creates a second self of an individual which is a mirror of the mind, belief and attitude of how that person perceives him/her self identity. 
Self-representation in the digital age is done through the extended versions of written and visual modes. The written representation has shifted from diaries, memoirs and autobiographies to blogs and status on social networking sites. The visual representation of oneself has shifted from self-portraits by artists to selfies by individuals. This modes are forms a new digital culture where they allows every individual to express their feelings and emotions and make their voice being heard. This paper aims to conceptualise how the marketer uses the concept of digital self through the selfie phenomenon in the offline context, and how this is becoming a part of the popular culture where the digital self is extended from the online sphere to the offline sphere.

\section{Literature Review}

\section{Popular Culture}

Popular culture is the accumulation of cultural elements of a country, region, and community. It consists of cultural product such as music, art, street fashion, literature, dance, popular television programs, radio, blockbuster cinema, newspaper headlines, and cultural role of models (Sinha, 2008). According to Trier-Bieniek \& Leavy, (2014), "Popular culture refers to the images, narratives, and ideas that circulate within mainstream culture. They are popular and known to the masses the most in a given society and they are exposed to the same dominant aspects of pop culture." The popular cultures such as films, drama and art, communication are used in order to bring social change. For instance, inspite of the knowledge of the people that tobacco, liquor and cigarettes are harmful for health, people still continue to smoke and drink. Also, people are well aware of the fact that fast food and junk food is not good for their health, however, they still continue to consume it (Appadurai, 1998). Through documentary films and new media this could be attempted to convince the audience in preventing from such consumption and can also force the producers and manufacturers of such goods to be more responsible regarding the type and form of content they use in manufacturing (Freeman, 2007).

Culture describes experience of the people of a particular region or country, their manner of deriving meaning, their narratives and their mode of symbolism (Sahlins, 1997). Further, consumer culture according to Slater, (2002) is a condition of consumption that mediates certain aspects of the social relations in the context of the culture. This consumption symbolically represents its relationship and affiliation with a community, lifestyle and identity, 
with the culture that it comes from. For the purpose of this, Arnould and Thompson (2005) added the Consumer Culture Theory in the pool of knowledge. According to Arnould and Thompson, Consumer culture theory, "refers to a family of theoretical perspectives that address the dynamic relationship between consumer actions, the marketplace, and cultural meaning (Arnould \& Thompson, 2005).”

\section{The Selfie Culture}

Selfie as a concept and practice has gradually moved from the being just a digital trend, to phenomenon to becoming a part of the popular culture. Selfies have become like a reflection of one's own self and one's action. People identify it with it because it represents their freedom, their true self and their manifestation. The associative nature of social networking sites thus informs the aesthetic dimensions of the selfie. This includes the articulation of self through ancillary systems of identification such as profiles, product affiliations, and popular culture. Each inflect digital identities by reinforcing communities structured around shared interest, from popular culture icons, to specific brands, to activities such as biking, running, yoga, having fun with friends and other fun and cool activities.

\section{Social Media Marketing}

India has seen a steep growth in the selfie phenomenon since the time the idea became a global trend. From celebrities, to politicians, to a common man everybody is taking selfie whether it is a party, trip, funeral or just a normal regular day. According to neuroscientists, selfies gives in individual agency and ability to look at oneself the same way as the world looks at them. Brands banked on this phenomenon, especially the brands catering to the youth. Social media marketing is at an ever growing trend where an entire campaign is run by keeping the selfies at the centre stage. For example, beauty brand Dove in its real beauty promotional strategy recently launched a selfie campaign where the consumers were asked to take their selfie after using a dove product and post it on the Facebook page of dove and get the opportunity to become the new face of dove on Women's Day. The entire contest was a month long theme based campaign which grabbed great attention from women across the country. Along with products even television series such as Master Chef India had also launched a selfie campaign where audience of the show were asked to prepare a dish using the Amul products which was the official sponsor of the show, take a selfie with the dish, send it on the whatsapp number of 
the show and get the chance to meet the three hosts and other participants of the show. The entire campaign used a perfect balance of television, Facebook, Twitter, Whatsapp and smart phones. Social media has created micro-celebrities, where the personal branding of an individual could be converted into the image of an entire organization. The aspirational value of creating a personal brand is a result of the dreams and utopian mindscape plays an archetypal role. The brands in order to be made a long term place in the mind of the consumers must move from the functional level to the symbolic level to the cultural level. Certain products also encouraged the consumers to tweet and re-tweet their selfies and win discount coupons on the online shopping sites. The entire process is usually easy to do and free of cost, with a guaranteed benefits for the consumers, encourages them to participate and thus making the campaign a success in consumer engagement. In 2014 alone almost every brand has conducted a selfie contest. The benefits of adopting this phenomenon is that it is highly cost effective, it has wide spread and can be instantly shared on Facebook, Instagram and Twitter, with the hash tags.

\section{Consumer Identity}

One of the factors that determine consumption is the affirmation of identity. Consumers seek to build some sort of congruity between themselves and brand so that the brand they use becomes meaningful to them. This whole process can be explained by McCracken's (1988) theory of meaning movement. Brands can be seen as a bundle of different types of benefits (product, social and psychological benefits) and associations. A brand is not only a product but also a symbol. A consumer selects a brand not only for what is does but also for what it expresses. Therefore, it is essential for him/her to select those brands that are in tune with the self-identity that he/she wants to construct and express (Krishna, 2014).

The accumulation of goods and services used in everyday life is a symbolic mechanism for the formation of identity. This assumes that the market appropriately represents the mythical and symbolic resources which help in building of identity narratives, inspite of all the contradictions, ambivalences, inconsistencies and instabilities (Arnould \& Thompson, 2005). The identity is centre to the selfie related behaviour. According to Levy (1981) there are various dimensions of consumers self consumption. Again the consumption and identity of a product is not only determined by the symbolism of the product but also the usage of the product. 
Self-concept defined as the totality of an individual's thoughts and feelings with reference to himself or herself as an object. The important thing about this concept is that we work with the consumers' own description of themselves, rather than using descriptions from outside observers. This means that each consumer describes his or her own view of himself or herself, in contrast to traditional personality tests that fit responses from consumers into some predetermined silos of personality traits. Self-image has several dimensions, namely, Actual self-concept; Ideal self-concept, Private self-concept, and Social self-concept. The youth today prefer to share their pictures in the virtual space over the need to do some exciting activity in the real world. Digital natives worships their alter self and shares their images at an unprecedented scale.

\section{Digital Self}

In the world of digital communication which at present is strongly dominated by social networking sites, the users get the opportunity to display them in the manner they want. Their profile page on various social networking sites is like a reflection of their being in the real world. Now this identity may be their actual self, their perceived self or their aspired self. The self conceived perception in the online platform is often called as the digital self. The digital self is created on the online communication with no intervention of feedback or external environmental factors. The digital self is not something other than their real self rather it can be the extended self of one's real identity. The digital self is described as, firstly, inwardly oriented; secondly, narrative in nature; thirdly, retractable and fourthly, multipliable. It is more of the reflection of one's inner world, which focuses on the thoughts, feelings, emotions and personalities of an individual rather than their physical attribute such as their height and weight. Rather the digital self is often represented in a manner in which the negatively perceived physical attribute of a person could be changed into a positively perceived digital representation.

\section{Selfie}

According to the Oxford Dictionary, "selfie" is "a photograph that one takes of oneself, typically one taken with a smart phone or webcam and shared via social networking sites" (Oxford Dictionaries, 2015). Selfies are the category of photographs taken by a person of its own self with a mobile phone, which in most of the cases is a smart phone. They are usually 
flattering and taken in a fashion that it appears to be casual. This phenomenon has caught large attention of the people since last few years. Most of the selfies are taken with smart phones with the phone held high at the arm's length, or taken with a selfie stick, or with the phone pointed towards the mirror or put directly in front of the face using the front camera where the selfie technology reads the hand sign shown by the photographer and sets an automatic 3 seconds timer. By the end of 2014, almost one trillion selfies had been taken globally, which were a third of the total number of pictures taken by the age group of 18-24 year olds. Although this phenomenon for a social networking site is a comparatively old one, research shows that it is going to increase steadily in the coming few years (Saltzman, 2014).

The history of selfie goes way back to 1839 when the American pioneer in photography, Robert Cornelius, produced a daguerreotype of himself which is the first photograph of the self taken (Cornelius, 2014). And name it "The first light picture ever taken, 1839" (Cornelius, 2013, Cornelius, 2014). In the 1900 the launch of portable camera by Kodak called the Brownie box camera led to the photographic self-portraiture becoming a more widespread technique. The method was usually by mirror and stabilizing the camera either on a nearby object or on a tripod while framing via a viewfinder at the top of the box ("Beginners guide to understanding and using a brownie box camera, 2014"). Russian Grand Duchess Anastasia Nikolaevna at the age of 13 was one of the first teenagers to take her own picture using a mirror to send to a friend in 1914. In the letter that accompanied the photograph, she wrote, "I took this picture of myself looking at the mirror. It was very hard as my hands were trembling." Photographic selfportraiture flourished in the 1970s when affordable instant cameras birthed a new medium of self-expression, capturing uncharacteristically personal insight into otherwise conservative individuals and allowing amateurs to learn photography with immediate results (Thomas, 2014). This practice transitioned naturally across to digital cameras as they supplanted film cameras around the turn of the millennium.

The first use of the word selfie in any paper or electronic medium appeared in an Australian internet forum on 13 September 2002. In Karl Kruszelnicki's Dr. Karl Self-service science forum, a post by Nathan Hope stated, "Um drunk at a mates $21^{\text {st }}$, I tripped ofer and landed lip first on a set of steps. I had a hole about $1 \mathrm{~cm}$ long right through my bottom lip. And sorry about the focus, it was a selfie ("A brief history of the selfie", Oxford dictionaries, 2013)." The 
concept of uploading group self taken photographs to the internet, although with a disposable camera not a smartphone dates to a webpage created by Australians in September 2001, including photos taken in the late 1900s. As early as 2003, Italian media artist Alberto Frigo started photographing every object his right hand uses. The lifelong project resulted in the first categorized collection of selfies showing the artist every time he brushed his teeth, every time he put on deodorant and so on (Brennan, 2015; Charlton, 2015; Wilson, 2015). The Sony Ericsoon Z1010 mobile phone, released in late 2003, introduced the concept of a front-facing camera. The Z1010's front-facing camera had a sensor for selflies and video calls.

According to Malone (2014), selfies comes with an inherit characteristics of narcissism, and is believed that the selfies brings with itself more destructive form of narcissism rather than healthy narcissism. Narcissistic behaviour is used to describe those who have grandiose selfimage and lack of concern for others. The emotional drain and fatigue can be overwhelming. Narcissism is about overly inflated self-image, arrogance and lack of compassion. According to Campbell et al. (2011), narcissism has three crucial parts: the self, interpersonal relationships and self-regulatory strategies.

\section{A Conceptual Framework: Selfie in Advertising}

The particular phenomenon of selfies is connected with the concept of happiness by the marketers. Psychological research on happiness has shown strong correlation between happiness and branding. Happiness has great relevance for branding as it creates a long term impact and eventually memory in the minds of the consumers. Selfies provides an inthemoment happiness when people are consuming any product or services. This ultimately has the potential of resulting in a long term brand loyalty. Prior research has found that consumption of certain products and brands make people happy, as owning certain brands, especially luxury brands are of great aspirational value to people. Non-verbal communication such as smiling has high level of reliability and it increases trustworthiness. there are several factors affecting such as smiling is a part of the emotional state, selfies are more about our own created self, it is a priory approved by the user, and it is a reflection of the most hidden self desires of the people. This along with the concept of digital self helps in understanding how an individual represents themselves in the digital space. 
Selfies benefits the consumers as it comes with an opportunity for them to create a brand of themselves. Personal branding is no more an exclusive domain of the celebrities to promote. Now in the age of social media sites every person has the potential to become a microcelebrity by promoting themselves on social networking sites and create their own brand image. Social branding movement has created grassroots "micro-celebrities" with increasing frequency (Kozinets \& Cerone, 2014).

The selfie phenomenon has been used for various advertising and promotional activities. Selfie contest, such as asking the consumers to enter in the selfie contest of a brand by taking a selfie while using a product and these pictures will have one or more promotional hashtags so that people can 'like' it and 'follow' the brand page to know what cool things are happening. Marketers are taking advantage of this phenomenon by using it as a part of their promotional strategies, where they encourage both existing and potential consumers to take a selfie with their product or service, and upload the photo on their social networking pages of Twitter, Instagram, Pinterest, and Facebook or send it to the brand through Whatsapp. The facial recognition technology then evaluates the in-the-moment emotions of this selfies. This user generated content enhances the insights and helps in understanding the consumer. There have been various versions of selfies such as welfie - for workout selfies, drelfie - for drunken selfie, bookshelfie - for taken in front of a bookshelf among others; helfie - health care selfie (Saltzman, 2014).

Selfie ad campaigns have been specially designed and created in order to use the selfie phenomenon which has become a part of the popular culture and a part of the daily lives of the people across the world. Marketers are creating various promotional contest and advertisements to indulge people with their brand and attempt to create a much deeper and personal level of connection between the brand and the people. For instance, Dove's \#BeautyIs campaign asked a group of teenage girls to take a selfie of the feature that they disliked the most. The motherdaughter then attended an event where their self-portraits were blown up and posted in a \#BeautyIs photo gallery. The goal of the seven-minute film is for the women to redefine their own beauty and see that insecurity often lies beneath the personal snapshots. Among others are Ponds selfie ad campaign, PNG Jewellers, reliance group's independence data \#SaluteSelfie, Adidas' \#Shoefie, Philips India with MTV India's \#StyleTurf contest, \#DoveSelfie contest, 
Government of India \#SelfieForIndia for increasing number of voters, Reebok's \#LiveWithFire campaign, Skybags’ \#BackIsTheNewFront campaign.

\section{Conclusion}

At present, most of the brands are using the selfie phenomenon in which the taker of a selfie is representing them and expressing their feelings. The key aim of the brands is both to widen their reach and also make the consumers share a part of their digital self with the brand. This approach not only helps the brands but it also makes the consumer feel as an important part of the brand. Again the entire debate on whether the adverting on television will suffer negatively due to the advertising internet has been in some way solved by the marketers. As they have started using one common campaign as a point of integration between the internet and television. Rather it is a perfect marriage between the old media and new media, of a selfportrait taken on smart phone, posted on social networking sites, is then shown to the larger audience on the television on various advertisements and soap operas.

The entire concept of selfies have been so much internalized that now with the selfies sticks, go-pro water proof digital cameras and drone camera people have now started taking pictures of their self doing various adventurous things and activities. A digital phenomenon started in 2013 is still it-thing even in 2016, which is to say a lot as the digital phenomenon has a tendency to become a trend real fast and the trend going away even faster.

Selfies ad campaign has been used for social cause marketing, brand promotion and advertising across the sector and across the categories. For instance, Prime Minister Narendra Modi in his 2014 general election campaign took selfies with the BJP followers during the entire campaign period and also took a selfie on the day of election after he voted. In 2015 Indian Prime Minister Narendra Modi led a social campaign to save girl child and launched it with a selfie ad campaign asking the citizens of the country on a monthly radio address to take selfie with their daughters and post/share it social media sites with hash tag \#SelfieWithDaughter. It was an attempt to recognize and celebrate the girl child as part of his 'Beti Bachao, Beti Padhao (Save the Daughter, Educate the Daughter) campaign. In an attempt to associate and interact with the young audience, Signature brand of premium whiskey launched a selfie campaign purely through the signature selfie mobile app. Most stylish signature selfie was selected and the 
winner got a private portfolio shoot with fashion photographer Atul Kasbekar. The signature selfie app also came with features such as 5second timer, pro tips, glam filters, airbrush, and effects. The interesting part is that all this campaigns are not just digital campaigns run on internet and smart phones but they have been used as a strategy by marketers for integrated marketing communications were the selfie contests are promoted on television ads, radio ads, print ads, social networking sites and internet at large. 


\section{References}

'A brief history of the selfie,' (2013). Huffington Post. Retrieved June 15, 2016 from http://www.huffingtonpost.in/entry/selfie-history-infographic_n_4101645.

Appadurai, A. (1998). Modernity at Large: Cultural Dimensions of Globalization. Minneapolis: University of Minnesota Press.

Arnould, E., \& Thompson, C. (2005). Consumer culture theory (CCT): Twenty years of rearch. Journal of Consumer Research, 31(4), 868-882.

'Beginners guide to understanding and using a brownie box camera,' (2014). Retrieved on May 24, 2016, from: http://www.brownie-camera.com/articles/petelutz/article.shtml.

Brennan, C. (2015). The most touching set of photographs you'll ever see!" Retrieved on July 20, 2016, from: http://www.thejournal.ie/lifelogging-alberto-frigo-1934573-Feb2015/. Campbell, J., Giglio, S., \& Pathak, P. (2011). Forced Sales and House Prices, The American Economic Review, 101(5), 2108-2131.

Charlton, A. (2015). Huawei Ascend P7 announced - this one's for the selfie lovers.

Retrieved on May 1, 2016 from www.mobilechoiceuk.com/news/29282/ huaweiascend-p7-announced---this-ones-for-the-selfie-lovers.aspx\#.U6M9N_ldW_i.

Cornelius. (2013). Self-portrait; believed to be the earliest extant American portrait photo. Print \& Photographs Online Catalog. Library of Congress. 1-5.

Cornelius, R. (2014). Self-Portrait: The First Ever "Selfie" (1839). Public Domain Review. 110.

Freeman, C. (2007). The 'reputation' of neoliberalism. Journal of the American Enthnological Society, 34(2), 252-267.

Glum, J. (2015). Millennials Selfies: Young Adults Will Take More Than 25,000 Pictures of Themselves During Their Lifetimes. Retrieved on April 10, 2016 from http://www.ibtimes.com/millennials-selfies-young-adults-will-take-more25000pictures-themselves-during-2108417.

Kozinets, R.V., \& Cerone, S. (2014). Between the Suit and the Selfie: Executives' Lessons on the Social "Micro-Celebrity", Micro-Celebrity, 6(2), 21-22.

Krishna, R. (2014). Consumer Behaviour. Oxford University Press. London, UK.

Levy, S. (1981). Interpreting Consumer Mythology: A Structural Approach to Consumer Behaviour. Jounrnal of Marketing, 45, 49-61. 
Malone, P. (2014). Dealing with Selifes - Narcissists and The Public Manager, Public Management, 14-18.

McCracken, G. (1988). Culture and Consumption, Bloomington, IN: Indiana University Press.

Oxford Dictionaries, (2015). Selfie Noun - Pronunciation - Oxford Advanced Learner's Dictionary, Retrieved May 1, 2016 from http://www.oxfordlearnersdictionaries.com/pronunciation/english/selfie.

Sahlins, M. D. (1997). Comment. Current Anthropology, 38(2), 272-276.

Saltzman, D. A. (2014). A $4^{\text {th }}$ of July Selfie, National Underwriter Life \& Health, 20-21.

Sinha, J. B. P. (2008). Creating enabling conditions for human development. The Social Engineer, 2, 8-25.

Slater, D. (2002). Modernity under construction: Building the Internet in Trinidad. In P. Brey, T. Misa and A. Rip (eds), Modernity and Techonology: The Empirical Turn, Boston: MIT Press.

Thomas, M. (2014). Stevie Nicks self-portraits shown for the first time: I never thought anyone would ever see these pictures, The Guardian, London.

The Second Self. (2015). Retrieved April 20, 2015 from http://search.proquest.com/docview/1561142555?accountid=82913

Trier-Bieniek, A., \& Leavy, P. (2014). Gender \& Pop Culture, Sense Publishers, USA.

Wilson, M. (2015). For 11 years, this man has taken photos of everything his right hand touches, Fast Company, 1-10. 